\title{
High level of vaccination and protection against hepatitis B with low rate of HCV infection markers among hospital health care personnel in north of Iran: a cross- sectional study
}

Saffar Hiva', Khoshayand Negar², Parsaei Mohammad-Reza ${ }^{3}$, Ghorbani Gholam-Reza³, Aarabi Mohsen³, Nadi Ghara Ali-Asghar ${ }^{4}$ and Saffar Mohammed-Jafar ${ }^{5^{*}}$ (D)

\begin{abstract}
Background: hepatitis B virus (HBV) and C virus ( $\mathrm{HCV}$ ) are among the leading causes of mortality worldwide. Health care personnel (HCP) are subjected to increased risk of these infections. Therefore, HBV vaccination and postvaccination serologic testing (PVST) are recommended for them. Our objectives in this study were investigate how well the vaccination guidelines for hospital $\mathrm{HCP}_{\mathrm{s}}$ were implemented. Moreover, the prevalence rates of $\mathrm{HBV}$ and $\mathrm{HCV}$ infections were calculated. To determine the presence of immunological memory, vaccinated personnel negative to antibody against HB surface antigen with one dose of HB vaccine were boosted.

Methods: From 1 July to 30 November 2017, a cross-sectional study among HCPs working in public hospitals were conducted. All HCPs from various professional categories potentially at risk of exposure to contaminated sources were included. The information was gathered via interview and self-administered questionnaire. The questions were focused on the demographic characteristics, HB vaccination and immunity status and time elapsed since initial vaccination series, and frequency of needelstick injuries during the past 12 months of their work. Moreover, the prevalence rate of HBV and HCV infections were calculated. To determine the presence of immunological memory, subjects negative to HBV seromarkers received a booster dose of the vaccine.

Results: A total of 186 out of 766 participants were male and nurses comprised $71 \%$ of personnel. Although all HCP were vaccinated, $84 \%$ of them completed the course and less than $5 \%$ of them received PVST. According to the results, $0.78,4.6$, and $83 \%$ were serologically positive to HBV surface antigen, antibodies against HBV core, and $\mathrm{S}$ antigens, respectively. Approximately, $91 \%$ of seronegative participants responded to a booster dose and only $0.91 \%$ of the personnel was anti-HCV positive.

(Continued on next page)
\end{abstract}

\footnotetext{
* Correspondence: Saffar@softhome.net

${ }^{5}$ Research Center for Pediatric Infectious Diseases, Department of Pediatric Infectious Diseases, Bu-Ali Sina Hospital, Mazandaran University of Medical Sciences, Pasdaran Bolv, Sari, Iran

Full list of author information is available at the end of the article
}

(c) The Author(s). 2020 Open Access This article is licensed under a Creative Commons Attribution 4.0 International License, which permits use, sharing, adaptation, distribution and reproduction in any medium or format, as long as you give appropriate credit to the original author(s) and the source, provide a link to the Creative Commons licence, and indicate if changes were made. The images or other third party material in this article are included in the article's Creative Commons. licence, unless indicated otherwise in a credit line to the material. If material is not included in the article's Creative Commons licence and your intended use is not permitted by statutory regulation or exceeds the permitted use, you will need to obtain permission directly from the copyright holder. To view a copy of this licence, visit http://creativecommons.org/licenses/by/4.0/ The Creative Commons Public Domain Dedication waiver (http://creativecommons.org/publicdomain/zero/1.0/) applies to the data made available in this article, unless otherwise stated in a credit line to the data. 
(Continued from previous page)

Conclusion: Most HCP received full HBV vaccination course. Although a minority did PVST, the HBV vaccineinduced long-term protection and HB vaccine booster were not required. Therefore, policies should be made to increase the rate PVST after immunization. According to the results, the HCV infection rate was low and thus prerecruitment screening was not necessary.

Keywords: Health care personnel, Hepatitis B virus, Hepatitis C virus, HBV vaccination coverage, HBV booster

\section{Background}

Chronic hepatitis $\mathrm{B}$ and $\mathrm{C}$ infections are among the major public health issues and also among the leading causes of liver-related diseases and mortality in the world $[1,2]$.

According to the World Health Organization's (WHO) estimation, approximately 257 million persons are living with chronic hepatitis B (HBV), which led to more than 887,000 deaths in 2015 [3]. In addition, studies found globally nearly 122 to 185 million people are anti-HCV antibody positive [4] WHO estimated that in year 2016, approximately 399,000 people died from HCV related illnesses [5]. After childhood, the main routes of transmission are percutaneous sharp injuries, sexual and mucosal exposure to infected blood/body fluids (B/BF) [6-8].

Health Care Personnel (HCPs) are typically exposed to injuries by sharp instruments in the course of their duty. Injuries by sharp objects and related risk of infections represent the major risks related to occupational health and safety of HCPs worldwide [9-11]. According to data provided by the $\mathrm{WHO}$, there are approximately 36 million HCPs worldwide, of whom around 3 million/ year receive an injuries with an occupational instruments with nearly 2 million exposure to $\mathrm{HBV}$ and 1 million to HCV [12]. The limited available information about sharp injuries causing transmission of $\mathrm{HBV}, \mathrm{HCV}$ and HIV indicated 0.42 HBV infection, 0.05-1.3 HCV infection and 0.04-0.32 HIV infection per 100 sharp injuries [13]. $\mathrm{HBV}$ is a vaccine-preventable disease [6-8] and $\mathrm{HCV}$ is a treatable infection [5].

A range of measures and interventions can be used to minimize the transmission rates among HCPs [9-11]. However, immunization of HCP against the risk of HBV is considered to be an additional most effective strategy for prevention and protection from $\mathrm{HBV}$ infection [6$11]$. In this regard, several international agencies $[14,15]$ and advisory committees on immunization practices (ACIP) in different countries [16, 17], including Iran [14], recommended that all HCPs at risk of exposure to $\mathrm{B} / \mathrm{BF}$ should be vaccinated against HBV infection. Moreover, guidelines suggest that vaccinated HCP should verify their immunity status within 1-2 months after completion of the course $[5-7,14,16,17]$. Despite these recommendations and effective protection profile provided by immunization among vaccinated personnel, international studies have reported suboptimal and varying vaccination coverage rates among HCP in different countries and even among various subgroups within the same country. For example, the reported rates of complete HBV vaccination was $24.7 \%$ in Africa [15], $63.4 \%$ in US [18], and $85-100 \%$ in EU countries including Poland $[19,20]$. In addition, results of studies on the immunogenicity of HBV vaccine among adults, including $\mathrm{HCP}$, indicated $10-20 \%$ non-responsiveness among vaccinated adults $[6-8,21]$. In the case of exposure, having a good knowledge of HCP immunity status is important for appropriate post-exposure management. Unknown status is a cause of anxiety in both personnel and health professionals responsible for their management. This may result in hasty decisions regarding prophylactic measure and unnecessary use of HBV immunoglobulin (HBig) [16]. Despite these recommendations, a minority of vaccinated personnel documented their post-immunization status.

This study was designed to determine how well the guidelines for HBV immunization of HCP had been implemented. Moreover, the point prevalence of $\mathrm{HBV}$ infection seromarkers and $\mathrm{HCV}$ seroprevalence among different subgroups of HCP working in hospitals was measured. Moreover, to assess the durability of vaccineinduced immunity and protection, immunologic responses to an $\mathrm{HB}$ vaccine booster dose administration in personnel seronegative to all $\mathrm{HBV}$ infection seromarkers was evaluated.

\section{Methods}

This descriptive-analytical cross-sectional study was conducted from 1-July to 30-November 2017, to investigate the HB immunization status and post- vaccination serological testing (PVST), HB infection seromarkers, and $\mathrm{HCV}$ infection prevalence among HCP working in the public hospitals in the western areas of Mazandaran Province in North of Iran. The west of Mazandaran Province North of Iran, consist of 8 main districts. In each main district, one public hospital responsible for medical services to inhabitant exist. For this study purpose 4 out of 8 hospitals were randomly selected. In the selected hospital all eligible HCP from various professional categories deemed as the representative of all HCPs working in the region were recruited to participate 
in this study. In each hospital, selection and recruitment of eligible personnel was supervised by hospital nurses responsible for infection control and prevention associated with one of the author.

An HCP is defined as a person from the following category, who has professional contact with patients and/or is potentially at risk of exposure to contaminated sources inside hospitals: physicians, nurses and nursing aids, midwives, laboratory staff, and cleaners (logistic personnel involved in the waste disposal).

The information collected from HCP was done via interview and a self-administered authors made questionnaire (presented an additional file No 1), The questions focused on the age, sex, marital status, history of major surgery duration of work, and/or blood transfusion, IVDU and also on the primary vaccination status and the number of vaccine doses received, PVST status, time elapsed since the primary vaccination, and possible receipt of additional doses of $\mathrm{HB}$ vaccine and/or Hepatitis B immune globulin (HBIg) and the possible frequency of sharp instruments incident in the past 12 months of their work were sought. The research population was comprised of healthy HCP working in hospital. Those with serious systemic or metabolic disorders, malignancies or immune deficiencies, and those who received blood/plasma within the past 6 months were excluded. The study protocol used the standard ethical guidelines and was approved by the Ethics Committees of Mazandaran University of Medical Sciences (Sari: 3087-JR, Mazums, Rec. 1390.3087) and Tehran University of Medical Sciences (318563-37,970-30-01-97). After obtaining informed written consent, and filling an anonymous questionnaire $5 \mathrm{ml}$ of venous blood of all participants was collected and stored at $-20^{\circ} \mathrm{C}$ to measure HBV serological markers: [HBV surface antigen (HBsAg), antibodies against HBsAg (Anti-HBs) and against HBV core antigen (Anti-HBc)]. The seromarker concentration was measured using ELISA according to the manufacturer's instructions (Quantitative Anti-HBs, HBsAg conversion ULTRA, qualitative Anti-HBC, all kits from DIA; PRO. Diagnostic Bioprobes Srl, MianoItaly). The in-vitro diagnosis of $\mathrm{HCV}$ infection was done using a third-generation ELISA, which was sensitive for the detection of IgG-class antibodies against the viral structural protein (HCV-A6, 3rd generation immunoassay, DIA.PRO). Finally, the equivocal test results were rechecked.

Full vaccination was defined as receiving three doses of $\mathrm{HBV}$ vaccine. The vaccinated individuals with antiHBs titers > $10 \mathrm{IU} / \mathrm{L}$ were considered immune; whereas, vaccinated $\mathrm{HCPs}$ with positive titers of both anti-HBs and anti-HBc were regarded as having immune derived from natural $\mathrm{HB}$ infection (breakthrough infection). Cases with isolated anti-HBc positivity without $\mathrm{HBsAg}$ were considered possibly infected to $\mathrm{HBV}$ and followed accordingly. Positive results for $\mathrm{HBs} \mathrm{Ag}$ were considered as breakthrough infection and possible vaccine failure. Anti-HBs antibodies titer less than 10 were considered to be nonseroprotected and offered to receive one booster dose. Four to 6 weeks after booster injection, anti-HBs concentration measured. Seroconversion was defined as the presence of immune memory. Persons with isolated anti-HBs titers $>250 \mathrm{IU} / \mathrm{L}$ vaccinated for more than 10 years earlier without receiving any additional dose of $\mathrm{HB}$ vaccine or HBig was arbitrarily considered to be having immune by natural booster. All participants positive to anti-HCV antibody were retested and followed appropriately. Those positive for isolated anti-HBc and subjects positive for anti-HCV antibody were examined by PCR methods. (Ampli SensR HCVFRT, A analytical sensitivity, and Ampli SensR HBVFRT, A analytical sensitivity).

\section{Statistical analysis}

Collected data was analyzed using SPSS version16.0. The descriptive statistical method was used in the form of mean and standard deviation (SD) for age, duration of work, immunization at the confidence interval of 95\% $(\mathrm{CI}=95 \%)$. In addition, the frequency of variables among studied HCP was used to calculate collected data. The Chi-Square and Student t-test were used to find differences between variables. Results were considered to be statistically significant when the $p$-value was less than 0.05 .

\section{Results}

Among 914 eligible HCP, 776 HCP (83.80\%) consented to participate in the study. Of them, $186(24.28 \%)$ were male and $580(75.72 \%)$ were female. The number of cities population, eligible and participated hospital HCPs, with their demographic characteristics, mean age and mean duration of working in Table 1, relative contribution of various professions distribution of each job categories participated in this study in Table 2 and vaccination status, $\mathrm{HBV}$ and $\mathrm{HCV}$ infection seromarkers in Table 3 are presented. Approximately $73.5 \%$ of personnel were married, one person without any evidence of infection was IVDU. Overall, $42.4 \%$ of HPCs experienced $\geq 1$ needelstick injuries in their last 12 months of work.

$\mathrm{HB}$ vaccination and infection status: all $\mathrm{HCP}$ participated in this study were vaccinated against HB. However, $122(15.92 \%)$ participants did not complete the vaccination course, that 48 and 74 of them received one and two doses, respectively. Of all vaccinated personnel, only $37(4.83 \%)$ received anti-HBs antibody serological testing on schedule. However, 155 out of 766 (20.23\%) $\mathrm{HCP}$ received serological anti-HBs testing because of 
Table 1 The number of cities population, eligible and participated hospital HCPs, with their Demographic characteristic based on their own district in the west of Mazandaran province, North of Iran

\begin{tabular}{lllllll}
\hline Districts & Districts $\times 10^{3}$ population & Eligible HCP & Participated HCP (\%) & $\begin{array}{l}\text { Mean age year } \\
\text { /range }\end{array}$ & Mean duration of work year /range & Male/ Female \\
\hline Nour & 195 & 187 & $154(82.3 \%)$ & $33.47 / 22-59$ & $13.22 / 1-26$ & $41 / 113$ \\
Chalus & 220 & 316 & $235(74.3 \%)$ & $33.85 / 22-58$ & $12.93 / 1-27$ & $64 / 171$ \\
Tonekabon & 185 & 175 & $148(84.5 \%)$ & $34.59 / 22-59$ & $12.76 / 1-25$ & $32 / 116$ \\
Ramsar & 110 & 236 & $229(97 \%)$ & $34.06 / 22-60$ & $12.17 / 1-30$ & $49 / 180$ \\
Total & 710 & 914 & 766 & $33.75 / 22-60$ & $12.77 / 1-30$ & $186 / 580$ \\
\hline
\end{tabular}

needlestick injuries during their work's experience. Of them, 93 subjects $(60 \%)$ with one dose of $\mathrm{HB}$ vaccine were boosted. A total of 6 out of 766 subjects were HBsAg positive: $0.78 \%$ (95\% CI: $-0.104-1.698)$; in addition, 36 out of 766 were ant-HBc positive: $4.69 \%$ (95\%CI: 2.57-6.69), among whom 32 cases were also ant-HBs positive (subclinical resolved HB infection). None of the participants with isolated anti-HBc was HBV-DNA PCR positive. There was not any correlation between the age, and duration of work, with $\mathrm{HBsAg}$ and/or anti-HBc positive rates $(\mathrm{P}=0.850)$. From 766 screened HCPs, 636 (83\%) (95\% CI: 81.286.7) showed isolated anti-HBs antibody titers of more than $10 \mathrm{IU} / \mathrm{L}$ (seroprotected) and $88(11.48 \%)$ (95\% CI: $8.8-12.3 \%$ ) were susceptible to HB infection. There was no significant difference between fully vaccinated and incomplete vaccination and the gender (df:1, for both variable, P:NS), these data all presented in Table 4. In this study the point prevalence of natural boosting was 144/766 (18.79\%). These data are presented in Table 3.

\section{Boosting study}

In this study, out of 88 personnel negative protective titers of anti-HBs, 78 including 4 cases with isolated anti$\mathrm{HBc}$ agreed to participate in the boosting study. Four to 6 weeks after the first dose of $\mathrm{HB}$ vaccine booster administration, $71(91 \%)$ participants including all 4 subjects positive for anti-HBc responded to boosting and seroconverted. (Response rate: 67 of 74 (90.5\% Vs 4 of 4 (100\%).

\section{$\mathrm{HCV}$ antibody test}

Among 766 studied HCP, 7 (0.91\%) cases (95\% CI: 0.331.79) were positive to $\mathrm{HCV}$ antibody. Of those 5 cases consented to participate and were tested by HCV-RNA PCR. According to the results, none of them was positive.

\section{Discussion}

Study showed that all participants were immunized against $\mathrm{HB}$, but nearly $16 \%$ of them did not complete their vaccination course. However, a minority of vaccinees performed PVST. Most of studied HCPs were young in their age and work. Based on our data, $83 \%$ of studied subjects were serological immune to HBV infection, 0.78 and $4.6 \%$ showed evidence of chronic and resolved HB infection, respectively. Although $12 \%$ of vaccinated personnel were serologically susceptible to $\mathrm{HBV}$, most of them retained their specific immune memory demonstrated via response to a $\mathrm{HB}$ vaccine booster dose injection. The prevalence rate of anti-HCV was low. Finally, study results indicated that more than $42.4 \%$ of HCPs experience at last one NSIs in their work within the preceding year.

Based on this study findings most studied personnel were fully vaccinated. This proportion is one of the highest rates of vaccination coverage among $\mathrm{HCP}$ with the reported prevalence in Iran [22, 23] and other countries $[15,18-20,24-27]$. The reported rates of HBV immunization in HCP from both developed and developing countries varied widely $[15,18-20,24-27]$. Whereas, only $11.4 \%$ of Cameroonian HCP were fully

Table 2 Relative Contribution of various professions distribution of different job categories participated in the study according to their own hospital in the west of Mazandaran province, North of Iran

\begin{tabular}{|c|c|c|c|c|c|c|}
\hline \multirow[t]{2}{*}{ Districts } & \multicolumn{6}{|c|}{ Professional categories number } \\
\hline & Nurses & Midwives & Laboratory technicians & Physicians & Cleaner & total \\
\hline Nour & 113 & 10 & 19 & 9 & 3 & 154 \\
\hline Chalus & 165 & 19 & 32 & 14 & 5 & 235 \\
\hline Tonekabon & 105 & 9 & 21 & 10 & 3 & 148 \\
\hline Ramsar & 164 & 17 & 29 & 13 & 6 & 229 \\
\hline Total & 547 & 55 & 101 & 46 & 17 & 766 \\
\hline
\end{tabular}


Table 3 Profiles of HB vaccination status, HBV and HCV infections seromarkers among different professions of hospital HCPs in Mazandaran province, North of Iran

\begin{tabular}{|c|c|c|c|c|c|c|c|}
\hline \multirow[t]{2}{*}{ Job categories total number } & \multicolumn{2}{|l|}{ Vaccination Status } & \multicolumn{5}{|c|}{ Hepatitis Seromarkers } \\
\hline & Full $n=644(84 \%)$ & $\begin{array}{l}\text { Incomplete } \\
n=122(15.9 \%)\end{array}$ & $\begin{array}{l}\text { anti-HBs } \\
\mathrm{n}=636(83 \%)\end{array}$ & $\begin{array}{l}\text { anti-HBC } \\
\mathrm{n}=36(4.69 \%)\end{array}$ & $\begin{array}{l}\mathrm{HBsAg} \\
\mathrm{n}=6(0.78 \%)\end{array}$ & $\begin{array}{l}\text { Natural boosting } \\
\mathrm{n}=144(18.79 \%)\end{array}$ & $\begin{array}{l}\text { Anti-HCV } \\
n=7(0.91 \%)\end{array}$ \\
\hline Nurses $n=547(71.4 \%)$ & $461(84.72 \%)$ & $86(15.72 \%)$ & $466(85.19 \%)$ & $14(2.55 \%)$ & $3(0.54 \%)$ & 99 (18.09\%) & $4(0.73 \%)$ \\
\hline Laboratory staff $n=101(13.1 \%)$ & $84(83.16 \%)$ & $17(16.8 \%)$ & $81(80 \%)$ & $9(8.9 \%)$ & $2(1.98 \%)$ & $23(22.77 \%)$ & $2(1.98 \%)$ \\
\hline Midwives $n=55$ (7.1\%) & $46(83.63 \%)$ & $9(16.3 \%)$ & $41(74.54 \%)$ & $6(10.6 \%)$ & 0 & $11(20 \%)$ & 0 \\
\hline Physicians n = 46 (6.0\%) & $42(91.5 \%)$ & $4(8.7 \%)$ & $38(82.6 \%)$ & $4(8.6 \%)$ & $1(2.1 \%)$ & $6(13 \%)$ & 0 \\
\hline Cleaners $n=17$ (2.2\%) & $11(64.7 \%)$ & $6(35.3 \%)$ & $10(58.8 \%)$ & $3(17.64 \%)$ & 0 & $5(29.4 \%)$ & $1(5.85 \%)$ \\
\hline
\end{tabular}

vaccinated against $\mathrm{HB}$ [26], nearly all surgical nurses in Polish hospitals were immunized [20]. The self-reported rates of complete vaccination detected in national survey was $63.4 \%$ in the United States of America [18], 55.4\% in India [24], and $60 \%$ in China [25]. However, this rate was $85-100 \%$ among health care providers working in different European Union countries [19, 20]. Similar to our findings, during recent years relatively high rates of immunization against HB in HCPs working in hospitals, from different regions of Iran were reported [22, 23]. In this regard, to estimate the $\mathrm{HB}$ vaccination coverage rates among Iranian HCP two systematic reviews and meta-analysis were conducted [22, 23]. In the first study [22], 6311 subjects from 21 articles were included. The history and the complete vaccination rates were estimated to be 86.9 and $70.3 \%$, respectively [22]. The second one, performed among 4104 Iranian physicians and nurses, showed that the history and full $\mathrm{HB}$ vaccination rates were $88.7,93.5$ and $73.1 \%, 76 \%$, respectively [23]. The most possible explanation for the higher rates of $\mathrm{HB}$ vaccination coverage in Iran may be due to easy access to free $\mathrm{HB}$ vaccine in the hospitals across the country. In addition, the important roles of the occupational health promotion and infection prevention/control committee established in most hospitals should also be considered.

Our data showed that only a minority of surveyed subjects $(<5 \%)$ checked their anti-HBs titers on the recommended schedule. The probable reasons for this rate could be explained as follow: 1) The employees should be charged for PVST, which is a rather expensive test, 2) Many of them believe that vaccination is associated with full immunity, so they feel no requirement for PVST. Actually it appears that most HCPs do not have enough or accurate information about PVST. However, during their work's experience, nearly $20 \%$ personnel did anti-Hbs serological testing as part of their postexposure management. After HBV vaccination, serological testing to document immune response is recommended for persons whose post-exposure clinical management depends on the knowledge of their immunity status. However, the global rates of post-vaccination serotesting varied greatly and the majority of the vaccinated HCP did not check their anti-HBs levels after vaccination [24, 27-30]. Despite applying PVST in the vast majority of EU countries, serologic testing rates were markedly different among these countries [19]. For example, data from a large teaching hospital in France showed that $65 \%$ of vaccinated personnel tested their anti-HBs antibody on completion of immunization [19]; whereas, this rate in a multicenter study in Poland was $24.9 \%$ [30]. Similarly, in a study on medical students from São Paulo in Brazil, out of 675 participants, 48.9\% were fully vaccinated and only $34.8 \%$ of vaccinated subjects performed antibody testing [27]. Based on our data and the literature results, particular attention should be

Table 4 Profiles of immunity of hospital HCPs in relation to their vaccination status and gender ${ }^{\mathrm{a}}$, Mazandaran province, North of Iran

\begin{tabular}{lclll}
\hline & \multicolumn{2}{l}{ Vaccination Status $^{\mathrm{b}}$} & & \\
\cline { 2 - 5 } & Full $\mathrm{n}=612$ & susceptible $\mathrm{n}=73$ & incomplete vaccination $\mathrm{n}=112$ & susceptible $\mathrm{n}=15$ \\
\cline { 2 - 5 } & Immune $\mathrm{n}=539$ & 57 & 77 & 12 \\
females & 403 & 16 & 20 & 3 \\
males & 136 & 73 & 97 & 15 \\
total & 539 & & & 37 \\
\hline
\end{tabular}

a: Statistical analysis: $\mathrm{df}=1 \mathrm{P}$ for both, Non-significant

b: Of 766 studied HCPs, 42 were naturally infected the remainder 724 were included 
given to post-vaccination antibody testing to ensure that vaccinated personnel at risk have developed adequate immunity against HB infection. Therefore, it seems reasonable that testing of antibody on completion of vaccination should be incorporated into a vaccination program on a mandatory basis.

The results from several long-term follow-up studies on the $\mathrm{HB}$ vaccinated people indicated that the vaccineinduced antibody concentration declined with time and could reach to non-protective or even undetectable titer without further booster injection or subclinical breakthrough HB infection, 15-23 years after the initial immunization [31-33]. Based on our surveyy, protective antibody titers remained in $83 \%$ of the screened participants many years after the primary course of HB vaccination. However, study showed that 93 out of 766 (12.0\%) of $\mathrm{HCP}$ were boosted with $\geq 1$ dose of $\mathrm{HB}$ vaccine during their professional career. This high-rate of seroprotection may be due to the younger age of personnel (mean age 33, years), shorter time elapsed since the primary course of vaccination (46.5\% of them had work's experience of fewer than 10 years), furthermore $12.0 \%$ received an additional dose of $\mathrm{HB}$ vaccine, occurrence of subclinical breakthrough infection in $4.6 \%$ of them, and development of natural boosting in nearly $19 \%$ of subjects during their career).

Based on our arbitrary definition for this study, 144 persons showed evidence of natural boosting during their profession. The prevalence of natural boosting varied in different settings across the world, obtained from long-term prospective studies. In a 20-year follow-up study on immunized children born from HBsAg positive mothers, the reported rate of natural boosting was 5.93\% [31]. The rates reported in a 22-year prospective study on native Alaskan people was $27 \%$ [32], and $23 \%$ in a 23-year follow-up study in China [33]. However, this rate in our earlier cross-sectional study on young adults vaccinated in infancy in Mazandaran Province was 19\% [34]. The mechanism of natural boosting was uncertain. However, it may result from a cross antigen reaction or from a transient $\mathrm{HB}$ viremia with no other evidence of HB infection. This phenomenon possibly leads to maintaining long-term immunity and memory against $\mathrm{HB}$ infection [35].

In this study, 0.78 and $4.6 \%$ of studied subjects were $\mathrm{HBsAg}$ and anti-HBc positive. These rates were not significantly different among those who were fully or incompletely vaccinated and also there was no correlation with their work's experience. The frequency of $\mathrm{HB}$ infection in HCPs depends on the HBsAg prevalence in the general population where they work and the frequency of exposure to $\mathrm{B} / \mathrm{BF}$ in their career [6-11]. Therefore, the reported prevalence varied considerably among HCPs working in different countries, and even within the same country. More than two decades after successful implementation of the universal infantile $\mathrm{HB}$ immunization along with $\mathrm{HB}$ vaccination of the highrisk groups and adolescents catch-up immunization program in the world and Iran, the prevalence of $\mathrm{HB}$ infection and HBsAg carrier reduced significantly among general population and some high-risk groups including $\mathrm{HCP}$ in the many countries and even within the same country in the world $[2,36]: 0.3 \%(0.15-2.7)$ in USA [37], 0.9\% (0.1-4.4\%) in EU [38], $1 \%$ in India [24], 4.7\% in Indonesia [39], and $8.7 \%(5.2-14.3 \%)$ in Cameron [26]. The prevalence of $\mathrm{HB}$ infection in Iran reduced in line with its global downward trend [40, 41]. In this regard, the national prevalence of $\mathrm{HBsAg}$ and anti-HBc positive cases was estimated to be, respectively, $1.84 \%$ (95\%CI: $1.61-2.09)$ and $13.59 \%(95 \% \mathrm{CI}: 12.92-14.29)$ in the range of $0.76-5.10 \%$ and $4.17-36.9 \%$ [40]. The frequency rates of $\mathrm{HBsAg}$ and anti-HBc in this study were lower than those reported in Iranian general population. It was similar to our recent findings from other teaching hospitals in Mazandaran Province, and some other parts of the country [42, 43]. However, the prevalence of HBsAg positivity in this study was higher than that the recent estimate among Iranian HCP: 0.4\% (95\%: 0.1-0.5) in the range of 0.3 and $4.1 \%$ [44]. Results showed that $4.6 \%$ of screened vaccinated personnel were anti-HBc positive, which in the majority of cases was associated with protective titers of ant-HBs antibody suggestive for resolved subclinical (breakthrough) HB infection. The frequency of positive rate was not significantly different among different profession. Symptomatic HB infection or HBsAg carrier status, following a successful $\mathrm{HB}$ immunization of HCP, was rare [6-8]. However, the reported prevalence of subclinical breakthrough $\mathrm{HB}$ infection in fully vaccinated $\mathrm{HCP}$ varied widely in the world. For example, the incidence rates were, respectively, 2.5, 2.5 , and $2.5 \%$ in the USA [45], Spain [46] and Japan [47] versus $16.4 \%$ in Poland [20], 24.7\% in India [24], and $70 \%$ in Albania [48]. The relatively low prevalence of $\mathrm{HB}$ infection reported in this and some other domestic studies could be attributed to the high rate of vaccination against HB among Iranian HCP [22, 23]. However, the role of the National Infants HB Immunization Program launched in 1993 in reducing the prevalence of HBsAg among Iranian population should not be ignored [40, 41].

According to our findings, approximately $12 \%$ of the vaccinated persons were serologically susceptible to $\mathrm{HB}$ infection. Three to 6 weeks after administering one dose of $\mathrm{HB}$ vaccine, $91 \%$ of boosted subjects responded and seroconverted, indicating the presence of long-lasting protective immune memory from the vaccination.

None of the international guidelines for $\mathrm{HB}$ immunization has recommended a routine 
administration of booster doses of $\mathrm{HB}$ vaccine or periodic anti-HBs antibody testing once the response to a full vaccination occurred in general, but special consideration for high-risk groups may be worthwhile [49]. $\mathrm{HCP}$ are regarded as a high-risk group to $\mathrm{HB}$ infection. Therefore, booster vaccination is strongly recommended for non-immune $\mathrm{HCP}$, regardless of endemicity in the area concerned [6-8, 14, 16, 17, 49]. A recent Cochrane review was not able to identify any randomized study to assess the benefit of booster vaccination in preventing HB infection [50]. However, periodic anti-HBs testing is recommended in some European countries [18]. Some authorities [51, 52] also recommended booster injection to serologically susceptible persons $[19,24,51,52]$. Our findings support the idea that no booster of $\mathrm{HB}$ vaccine is required after a successful primary vaccination. These findings are consistent with data published recently. The result from a long-term study, 10-31 years after the initial $\mathrm{HB}$ immunization on $\mathrm{HCP}$, indicated that none of the participants was $\mathrm{HBsAg}$ positive, $2.5 \%$ of them showed evidence of resolved $\mathrm{HB}$ infection during their work's experience, and approximately $23 \%$ of them had lost their seroprotection. After boosting, more than $94 \%$ of serosuseptible participants were seroconverted. Researchers concluded that $\mathrm{HB}$ vaccine provides long-term protection and thus booster vaccination is not necessary [45]. However, further studies in this area are still required. Nevertheless, highly infectious HB virus inoculum might overpower low/non-protective anti-HBs titers during the long professional life of HCP. In these situations, the administration of a booster dose of $\mathrm{HB}$ vaccine could be considered [6-8, 16, 17, 45, 51, 52].

This study showed that $0.91 \%$ of $\mathrm{HCP}$ were anti-HCV antibody positive. However, none of the PCR tested subjects were positive. This may be due to clearance of $\mathrm{HCV}$ infection by somebody, EIA test or HCV PCR were falsely reactive, and rarely that a person has intermittent or low level viremia. The prevalence of HCV infection varied markedly among different countries in the world. While central and East Asia, North Africa and the Middle East estimated to have high prevalence of infection rates $(>3.5 \%)$, most EU countries and Australia showed the prevalence of $1.5-3.5 \%$ and some other countries, including the most American countries, had the prevalence of less than $1.5 \%$. During recent years, an upward trend of HCV infection was observed in the world [4] and in Iran [53]. However, the prevalence of HCV infection in Iran seems to be as low as $0.3-0.5 \%$ among blood donors $[54,55]$. In this study, the prevalence of anti$\mathrm{HCV}$ antibody positivity was higher than those Iranian blood donors. Although, the risk of HCV infection, following occupational exposure, was not high $[10,11,16]$, nearly $1 \%$ of the prevalence rate found in this study indicated the necessity of appropriate post-exposure management in the cases of exposure to possible infectious sources. In this situation, regular follow-up evaluations are needed to diagnose possible $\mathrm{HCV}$ infection for early treatment [9-11]. However, because of low rate of $\mathrm{HCV}$ infection among the general population in Iran, pre-exposure screening of $\mathrm{HCPs}$ for $\mathrm{HCV}$ infection is not recommended.

For this study some limitations did exist. The most potential limitation was its reliance on self-reported data, which might influence the reliability of the findings and cause probable recall bias. Other limitation was that the $\mathrm{HBV}$ and HCV infection status before employment and the immune response to the initial $\mathrm{HB}$ vaccination series was not known. Moreover, the relation between the infection status and the NSIs was not investigated. Finally, for this study only hospital HCPs was investigated and health care providers in the primary health care centers and private clinics were not included, and this may influence the data collected for this group of personnel.

\section{Conclusion}

Based on the study findings, appropriate policies should be made to measure HB immunity before recruitment. Since high-rate seroprotection and long-term immune memory observed in this study, a booster dose of HB vaccine does not appear to be required. $\mathrm{HCV}$ infection screening before recruitment does not seem necessary. However, in the cases of exposure to highly susceptible HBV or HCV sources, as was recommended by experts and authorities for appropriate management, immediate anti-HBs and/or anti-HCV antibodies serologic testing is recommended [6-13].

\section{Abbreviations \\ HBV: Hepatitis B Virus; HCV: Hepatitis C virus; HCP: Health Care Personnel; PVST: Post vaccination serological testing; WHO: World health organization; EU: European countries; HBig: Hepatitis B immunoglobulin; \\ MAZUMS: Mazandaran University of Medical Sciences; TUMS: Tehran University of Medical Sciences; ELISA: Enzyme immune assay; IU/ L: International unit/ liter; PCR: Polymerase Chain Reaction; IVDU: Intravenous Drug Users}

\section{Acknowledgments \\ The researchers would like to thank the health care personnel for their participation in this study, as well as the professional health promotion committee staff in the hospitals, and the health staff in the deputy of health for their help in recruiting personnel and blood sampling.}

\section{Authors' contributions}

HS and NK involved in study design, literature search, laboratory testing and writing the paper. MP, MA, and GG.in Selection, recruiting, interviewing and blood sampling. AN; data collection and statistical analysis. MS participated in all study phases, (Conception, design, literature search, selection of eligible $\mathrm{HCP}$, data collection and interpretation of the results writing the paper and finalizing the version to be published. All authors read and approved the final MS.

\section{Funding}

This study was funded by Vice-chancellor for research and Technology MAZUMS No: (Sari: 3087-JR, Mazums, Rec. 1390.3087) and TUMS No: 
(318563-37970-30-01-97). The funders had no role in the design of study and collection, analysis, and interpretation and writing of manuscript.

\section{Availability of data and materials}

Obtained for this study will be available from the corresponding author at a reason all request.

\section{Ethics approval and consent to participate}

The study was provided ethical approval by the MAZUMS No: (Sari: 3087-JR, Mazums, Rec. 1390.3087) and TUMS No: (318563-37,970-30-01-97). The study obtained the consent of all participants and signed and informed consent form prior to the investigation. They were assured about confidentially and that their contribution would be on a voluntary bases as well as that they had full rights to withdraw from the study at any time.

\section{Consent for publication}

Not applicable.

\section{Competing interests}

The authors declare that they have no competing interest.

\section{Author details}

${ }^{1}$ Department of Pathology, Shariati Hospital, Teheran University of Medical Sciences, Tehran, Iran. ${ }^{2}$ Resident of Pathology, Shariati Hospital, Teheran University of Medical Sciences, Tehran, Iran. ${ }^{3}$ Mazandaran University of Medical Sciences, Sari, Iran. ${ }^{4}$ Health Sciences Research Center, Addiction Institute, Mazandaran University of Medical Sciences, Sari, Iran. ${ }^{5}$ Research Center for Pediatric Infectious Diseases, Department of Pediatric Infectious Diseases, Bu-Ali Sina Hospital, Mazandaran University of Medical Sciences, Pasdaran Bolv, Sari, Iran.

Received: 9 March 2020 Accepted: 3 June 2020

Published online: 12 June 2020

\section{References}

1. Stanaway JD, Flaxman AD, Naghavi M, Fitzmaurice C, Vos T, et al. The global burden of viral hepatitis from 1990 to 2013: findings from the global burden of disease study 2013. Lancet. 2016 Sep 10;388(10049):1081-8.

2. Schweitzer A, Horn J, Mikolajczyk RT, Krause G, Ott JJ. Estimations of worldwide prevalence of chronic hepatitis B virus infection: a systematic review of data published between 1965 and 2013. Lancet. 2015 Oct 17: 386(10003):1546-55

3. World Health Organization: Hepatitis B, Fact sheet. www.WHO.int/newsroom/fact-sheets/ detail/ hepatitis-B. 18 Jul/2019.

4. Mohd Hanafiah K, Groeger J, Flaxman AD, Wiersma ST. Global epidemiology of hepatitis $C$ virus infection: new estimates of age-specific antibody to HCV seroprevalence. Hepatol. 2013:57(4):1333-42.

5. World Health Organization: HCV, Fact sheet. Bwww.WHO.int/news-room/ fact-sheets/detail/hepatitis-C. $18 \mathrm{Jul} / 2019$.

6. World Health Organization. Heppatitis B vaccine. WHO position paper. 2017. WKLY Epidemiol Rec. 2017:27:369-92.

7. American Academy of Pediatrics. Hepatitis B. In: Kimberlin DW, Brady MT, Jackson MA, Long SS, editors. Redbook: 2018 Report on Infectious Diseases. 31st ed. Itasca: American Academy of Pediatrics; 2018. p. 402-28.

8. Van Damme P, Ward J, Shouval D, Wiersma S, Zanetti A, Schaffner W. Hepatitis B vaccines. In: Plotkin SA, Orenstein WA, Offit PA, editors. Vaccines. 16th ed. Saunders: Elsevier; 2013. p. 205-34.

9. Beltrami EM, Williams IT, Shapiro CN, Chamberland ME. Risk and management of blood-borne infections in health care workers. Clin Microbiol Rev. 2000 Jul;13(3):385-407.

10. Deuffic-Burban S, Delarocque-Astagneau E, Abiteboul D, Bouvet E Yazdanpanah Y. Blood-borne viruses in health care workers: prevention and management. J Clin Virol. 2011 Sep:52(1):4-10.

11. FitzSimons D, François G, De Carli G, Shouval D, Prüss-Ustün A, et al. Hepatitis B virus, hepatitis $C$ virus and other blood-borne infections in healthcare workers: guidelines for prevention and management in industrialised countries. Occup Environ Med. 2008 Jul;65(7):446-51.

12. Coppola N, De Pascalis S, Onorato L, Calò F, Sagnelli C, et al. Hepatitis B virus and hepatitis $C$ virus infection in healthcare workers. World J Hepatol. 2016;8(5):273-81. https://doi.org/10.4254/wjh.v8.i5.273 Review.
13. Elseviers MM, Arias-Guillén M, Gorke A, Arens HJ. Sharps injuries amongst healthcare workers: review of incidence, transmissions and costs. J Ren Care. 2014;40(3):150-6.

14. Schedule and Guidelines Group of Immunization Approved by National Immunization Technical Advistory Group. 2015. Ministry of Health and Medical Education. Center for Diseases Control and Prevention. Tehran 2015, Iran.

15. Auta A, Adewuyi EO, Kureh GT, Onoviran N, Adeloye D. Hepatitis B vaccination coverage among health-care workers in Africa: A systematic review and meta-analysis. Vaccine. 2018;36(32 Pt B):4851-60.

16. Schillie S, Trudy V. Murphy, MD, et al. CDC Guidance for Evaluating Health-Care Personnel for Hepatitis B Virus Protection and for Administering Postexposure Management. Recommendations and Reports. 2013:62(RR10);1-19.

17. European Consensus Group on Hepatitis B Immunity. Are booster immunisations needed for lifelong hepatitis B immunity? Lancet. 2000 22(355):561-5.

18. Byrd KK, Lu PJ, Murphy TV. Hepatitis B vaccination coverage among healthcare personnel in the United States. Public Health Rep. 2013 Nov-Dec 128(6):498-509.

19. De Schryver A, Claesen B, Meheus A, van Sprundel M, François G. European survey of hepatitis B vaccination policies for healthcare workers. Eur J Pub Health. 2011;21(3):338-43.

20. Ganczak M, Ostrowski M, Szych Z, Korzeń M. A complete HBV vaccination coverage among Polish surgical nurses in the light of anti-HBC prevalence: A cross-sectional sero-prevalence study. Vaccine. 2010;28(23):3972-6.

21. Ganczak M, Skonieczna-Żydecka K, Drozd-Dąbrowska M, Adler G. Possible Impact of 190G > A CCR2 and $\Delta 32$ CCR5 Mutations on Decrease of the HBV Vaccine Immunogenicity-A Preliminary Report. Int J Environ Res Public Health. 2017;14(2):166

22. Sayehmiri K, Azami M, Nikpey S, Borji M, Sayehmiri F. Hepatitis B vaccination coverage in health personnel of Iran: a systematic review and meta-analysis study. Iran J Epidemiol. 2015:11(3):1-10.

23. Azami M, Borji M, Ghanbari F, Nikpay S, Sayehmiri K. Hepatitis B vaccination coverage of physicians and nurses in Iran: a systematic review and metaanalysis study. J Birjand Univ Med Sci. 2015;22(4):304-15.

24. Sukriti PNT, Sethi A, Agrawal K, Agrawal K, Kumar GT, et al. Low levels of awareness, vaccine coverage, and the need for boosters among health care workers in tertiary care hospitals in India. J Gastroenterol Hepatol. 2008; 23(11):1710-5.

25. Yuan Q, Wang F, Zheng H, Zhang G, Miao N, et al. Hepatitis B vaccination coverage among health care workers in China. PLoS One. 2019;14(5): e0216598.

26. Ndongo CB, Eteki L, Siedner M, Mbaye R, Chen J, et al. Prevalence and vaccination coverage of hepatitis $B$ among health care workers in Cameroon: a national seroprevalence survey. Viral Hepa. 2018;25(12):1582-7.

27. DeSouza EP, Teixeira MS. Hepatitis b vaccination coverage and postvaccination serologic testing among medical students at a public university in Brazil. Rev Inst Med Trop Sao Paulo. 2014;56(4):307-11.

28. Aroke D, Kadia BM, Anutebeh EN, Belanquale CA, Misori GM, et al. Awareness and vaccine coverage of hepatitis B among Cameroonian medical students. Biomed Res Int. 2018;2018:3673289.

29. Loulergue P, Moulin F, Vidal-Trecan G, Absi Z, Demontpion C, et al. Knowledge, attitudes and vaccination coverage of healthcare workers regarding occupational vaccinations. Vaccine. 2009 Jun 24;27(31):4240-3.

30. Ganczak M, Topczewska K, Budnik-Szymoniuk M, Korzeń M. Seroprevalence of anti-HBC, risk factors of occupationally acquired HBV infection and HBV vaccination among hospital staff in Poland: a multicenter study. BMC Public Health. 2019;19(1):298 1-12.

31. Roznovsky L, Orsagova I, Kloudova A, Tvrdik J, Kabieszova L, et al. Long-term protection against hepatitis B after newborn vaccination: 20-year follow-up. Infection. 2010;38(5):395-400.

32. McMahon BJ, Dentinger CM, Bruden D, Zanis C, Peters $H$, et al. Antibody levels and protection after hepatitis B vaccine: results of a 22-year follow-up study and response to a booster dose. J Infect Dis. 2009;200(9):1390-6.

33. But DY, Lai CL, Lim WL, Fung J, Wong DK, et al. Twenty-two years follow-up of a prospective randomized trial of hepatitis $B$ vaccines without booster dose in children: final report. Vaccine. 2008;26(51):6587-91.

34. Saffar H, Ajami A, Saffar MJ, Shojaei J, Sotudeh-Anvari M et al. Prevalence of hepatitis B virus seromarkers in young adults vaccinated at birth; impact on the epidemiology of hepatitis B infection in Iran. Hepat Mon. 2014 May 1: 14(5):e17263. 
35. Pichichero ME. Booster vaccinations: can immunologic memory outpace disease pathogenesis? Pediatrics. 2009;124(6):1633-41.

36. Ott JJ, Stevens GA, Groeger J, Wiersma ST. Global epidemiology of hepatitis $B$ virus infection: new estimates of age-specific HBsAg seroprevalence and endemicity. Vaccine. 2012;30(12):2212-9.

37. Gish RG, Cohen CA, Block JM, Brosgart CL, Block TM, et al. Data supporting updating estimates of the prevalence of chronic hepatitis $B$ and $C$ in the United States. Hepatology. 2015 Nov;62(5):1339-41.

38. Hahné SJ, Veldhuijzen IK, Wiessing L, Lim TA, Salminen M, et al. Infection with hepatitis B and C virus in Europe: a systematic review of prevalence and cost-effectiveness of screening. BMC Infect Dis. 2013;13:181.

39. Muljono DH, Wijayadi T, Sjahril R. Hepatitis B virus infection among health Care Workers in Indonesia. Euroasian J Hepatogastroenterol. 2018;8(1):88-92

40. Hajarizadeh B, Mesgarpour B, Nasiri MJ, Alavian M, Merat S, et al. Estimating the prevalence of hepatitis $B$ virus infection and exposure among general population in Iran. Hepat Mon. 2017;17(8):e11715.

41. Salehi-Vaziri M, Sadeghi F, Almasi Hashiani A, Gholami Fesharaki M, Alavian SM. Hepatitis $B$ virus infection in the general population of Iran: an updated systematic review and meta-analysis. Hepat Mon. 2016 Apr 26;16(4):e35577.

42. Saffar MJ, Jooyan AR, Mahdavi MR, Khalilian A. Seroprevalence of hepatitis a, $B$, and $C$ and hepatitis $B$ vaccination status among health Care Workers in Sari -Iran. Ind J Gastroenterol. 2005;24(2):82-3.

43. Aminian O, Moaven Saidi M, Sadeghniiat K, Izadi N. Coverage and LongTerm Immunogenicity of Hepatitis B Vaccine in Health Care Workers. Arch Clin Infect Dis. 2016;11(4):e35758.

44. Sayehmiri K, Azami M, Borji M, Nikpay S, Chamani M. Seroprevalence of hepatitis B virus surface antigen ( $\mathrm{HBsAg}$ ) in Iranian health care workers: systematic review and meta-analysis study. J Occup Environ Health. 2016; 2(1):47-57.

45. Gara N, Abdalla A, Rivera E, Zhao X, Werner JM, et al. Durability of antibody response against hepatitis $B$ virus in healthcare workers vaccinated as adults. Clin Infect Dis. 2015 Feb 15;60(4):505-13.

46. Domínguez A, Urbiztondo L, Bayas JM, Borrás E, Broner S, et al. Serological survey of hepatitis B immunity in healthcare workers in Catalonia (Spain). Working Group for the Study of the immune status in healthcare Workers of Catalonia. Hum Vaccin Immunother. 2017;13(2):435-9.

47. Yanase M, Murata K, Mikami S, Nozaki Y, Masaki N, et al. Hepatitis B virus vaccination-related seroprevalence among health-care personnel in a Japanese tertiary medical center. Hepatol Res. 2016;46(13):1330-7.

48. Kondili LA, Ulqinaku D, Hajdini M, Basho M, Chionne P, et al. Hepatitis B virus infection in health care workers in Albania: a country still highly endemic for HBV infection. Albania. Infection. 2007;35(2):94-7.

49. Poorolajal J, Mahmoodi M, Majdzadeh R, Nasseri-Moghaddam S, et al. Longterm protection provided by hepatitis $\mathrm{B}$ vaccine and need for booster dose: a meta-analysis. Vaccine. 2010 Jan 8;28(3):623-31.

50. Poorolajal J, Hooshmand E. Booster dose vaccination for preventing hepatitis B. Cochrane Database Syst Rev. 2016;6:CD008256.

51. John TJ, Cooksley G. On behalf of the steering Committee for the Prevention and Control of infectious diseases in Asia. Hepatitis B vaccine boosters: is there a clinical need in high endemicity populations? J Gastroenterol Hepatol. 2005;20(1):5-10.

52. Batra V, Goswami A, Dadhich S, Kothari D, Bhargava N. Hepatitis B immunization in healthcare workers. Ann Gastroenterol. 2015 Apr-Jun;28(2): 276-80.

53. Taherkhani R, Farshadpour F. Epidemiology of hepatitis $C$ virus in Iran. World J Gastroenterol. 2015;21(38):10790-810.

54. Khodabandehloo M, Roshani D, Sayehmiri K. Prevalence and trend of hepatitis $C$ virus infection among blood donors in Iran: a systematic review and meta-analysis. J Res Med Sci. 2013 Aug;18(8):674-82.

55. Kafi-abad SA, Rezvan H, Abolghasemi H, Talebian A. Prevalence and trends of human immunodeficiency virus, hepatitis B virus, and hepatitis $C$ virus among blood donors in Iran, 2004 through 2007. Transfusion. 2009:49(10): 2214-20.

\section{Publisher's Note}

Springer Nature remains neutral with regard to jurisdictional claims in published maps and institutional affiliations.

\section{Ready to submit your research? Choose BMC and benefit from:}

- fast, convenient online submission

- thorough peer review by experienced researchers in your field

- rapid publication on acceptance

- support for research data, including large and complex data types

- gold Open Access which fosters wider collaboration and increased citations

- maximum visibility for your research: over $100 \mathrm{M}$ website views per year

At BMC, research is always in progress.

Learn more biomedcentral.com/submissions 